\title{
Desarrollo legal y jurisprudencia constitucional en Colombia sobre la protección del medio ambiente y los recursos hídricos ${ }^{* 1}$ Legal development and constitutional law in Colombia on the protection of the environment and water resources
}

\author{
Héctor Javier Dussán Bastidas \\ Abogado, candidato a magíster en derecho \\ público,Colombia \\ jdussanabogado@gmail.com \\ Juan Pablo Martínez Andrade \\ Abogado, candidato a magíster en derecho \\ público,Colombia \\ juanpamar22@hotmail.com
}

Recibido: 29/11/2018 Aprobado 30/04/2019

DOI: $10.25054 / 16576799.2645$

\section{RESUMEN}

En las últimas décadas, como consecuencia del cambio climático y las altas temperaturas presentadas durante el "Fenómeno del Niño", se ha acentuado en Colombia y el Departamento del Huila la escasez de agua en los acueductos municipales. Esta problemática que genera preocupación en las autoridades y en la población en general, ha despertado el interés en la academia a debatir si las diferentes disposiciones legales existentes la legislación colombiana son suficientes para hacer frente a la crisis ambiental y especialmente a la pérdida de recursos hídricos superficiales, lo cual afecta el acceso al líquido para el consumo humano.

En ese orden, a partir de la identificación y análisis del desarrollo legal y jurisprudencial de la Corte Constitucional de Colombia, relacionados con la protección ambiental y en especial al tema del agua, se advierte que desde el siglo XX a raíz de innumerables problemas suscitados por la actividad económica con impacto negativo en la salud humana, se dieron las primeras normas de contenido medioambiental, disponiendo algunas medidas sobre el uso del agua utilizada para el consumo humano, pasando por el Decreto Ley 2811 de 1974, el cual adoptó el Código Nacional de Recursos Naturales Renovables y de Protección al Medio Ambiente, y un profuso desarrollo normativo ambiental, hasta llegar a la Constitución Política de 1991 considerada como una "Constitución Ecológica". Desde ese momento, se ha intensificado la producción normativa y jurisprudencial en torno a la protección jurídica del agua como generadora de vida.

\section{PALABRAS CLAVE}

Escasez de Agua; Fenómeno del Niño; Recursos Hídricos; Zonas Estratégicas.

*Artículo de investigación

1 El presente artículo de investigación hace parte del proyecto de investigación denominado "Zonas estratégicas para la protección de recursos hídricos que surten de agua los acueductos municipales en el departamento del Huila”, para optar por el título de magíster en Derecho Público de la Universidad Surcolombiana. 


\begin{abstract}
In recent decades, as a result of climate change and the high temperatures presented during the so-called "El niño Phenomenon", there has been a marked lack of water in the municipal aqueducts in Colombia and the Huila region. This problematic that generates concern in the authorities and in the general population, has aroused the interest in the academy to debate if the different legal provisions in the Colombian legislation are sufficient to deal with the environmental crisis and especially the loss of surface water resources which affects access to the liquid for human consumption.

In that order, from the identification and analysis of the legal and jurisprudential development of the Constitutional Court related to environmental protection and especially to the issue of water, it was noticed that since the 20th century, due to innumerable problems caused by economic activity with negative impact on human health, the first environmental standards provided some corrective measures on the use of the water used for human consumption. Going by the Decree Law 2811 of 1974, which adopted the National Code of Renewable Natural Resources and Protection to the Environment, and a heavy regulatory environmental development, up to the political Constitution of 1991, considered to be a "green Constitution". The regulatory and jurisprudential production regarding the legal protection of water as a generator of life has intensified since then.
\end{abstract}

\title{
KEYWORDS
}

Shortage of Water; El Niño Phenomenon; Water Resources; Strategic Areas.

\section{INTRODUCCIÓN}

A partir del siglo XX, y ante los negativos impactos ambientales ocurridos, se ha visualizado claramente la voracidad con que la humanidad ha explotado los recursos naturales, dejando al descubierto la mala relación entre el desarrollo económico y la naturaleza.

La producción de materias primas, el consumo excesivo, la extracción minera, la expansión ganadera, la agroindustria y el crecimiento demográfico de la población, han llevado al límite la capacidad de resistencia del planeta y, a la par, las acciones para mitigar las consecuencias de esta problemática "resultan limitadas e insuficientes para dar respuesta a la cada vez más compleja situación global" (Mesa-Cuadros, 2013, p. 178).

El desmedido aprovechamiento de los recursos naturales renovables y no renovables, sumado a otros fenómenos climáticos regulares, han ocasionado problemas ambientales crónicos como la lluvia ácida, la reducción de la capa de ozono y el efecto invernadero. También, entre otras consecuencias adversas, han acelerado en los últimos años el deterioro, disminución y contaminación del agua dulce. Tan agudo es el panorama que la degradación ambiental es uno de los más graves problemas a los que en la actualidad se enfrenta el sistema mundial (Santos-Boaventura, 1998, p. 389).

El agua, que hace parte de los recursos naturales que se encuentran en peligro, referenciada en la Declaración de Dublín sobre el Agua y Desarrollo Sostenible llevada a cabo en Irlanda entre el 26 al 31 de enero de 1992, como "un recurso finito y vulnerable, esencial para sustentar la vida y el medio ambiente" (CEPAL, 1992, p. 2), escasea en el planeta de manera más recurrente y regular durante los ciclos atmosféricos secos, en razón a múltiples factores que impactan negativamente en el medio ambiente.

Colombia también ha padecido las consecuencias del deterioro del medio ambiente y el cambio climático a causa de la indebida intervención humana sobre los recursos naturales. Si bien es cierto que Colombia aún cuenta con un amplio y diverso inventario de sistemas ecológicos que proporcionan innumerables riquezas naturales como son los recursos hídricos, ha dejado de considerarse como una de las primeras potencias mundiales en disponibilidad de agua dulce; esto como consecuencia del ya mencionado desarrollo socioeconómico acentuado en los últimos años por 
la creciente demanda del preciado líquido para actividades agrícolas, industriales, energéticas y por supuesto para el consumo humano.

Las alteraciones climáticas que tienen efectos en el ciclo hidrológico, provocadas como se ha venido diciendo por la contaminación ambiental, la explotación indebida del uso del suelo, la tala de árboles etc., han contribuido finalmente al calentamiento global dando paso al "Fenómeno del Niño", caracterizado por periodos anuales con presencia de altas temperaturas, disminución de las precipitaciones y de los caudales de los ríos y quebradas.

El Departamento del Huila no escapa a la problemática ambiental y a los estragos que causa las temporadas secas; en los años 2015 y 2016, considerados estos últimos por la Organización Mundial Meteorológica como los años más cálidos desde que empezaron los monitoreos y mediciones del clima en 1880, se incrementaron los reportes de escasez de agua en los acueductos municipales, obligando a las autoridades locales a tomar medidas extremas como el racionamiento del servicio domiciliario.

Atendiendo a lo anterior, el presente artículo que hace parte de la investigación denominada: "zonas

disponible para el consumo humano. Según el Estudio Nacional del Agua realizado por el Instituto de Hidrología, Meteorología y Estudios Ambientales del año 2014 (IDEAM, 2014), 316 cabeceras municipales en Colombia pueden presentar problemas de desabastecimiento en épocas secas, lo que podría afectar a 11.530 .580 habitantes; poblaciones entre las cuales se destacan Chiquinquirá, Paipa, Floresta, Soracá, Manzanares, estratégicas para la protección de recursos hídricos que surten de agua los acueductos municipales en el Departamento del Huila", y que tiene como finalidad medir el cumplimiento del Artículo 111 de la Ley 99 de 1993; busca identificar y exponer el desarrollo de las principales normas y jurisprudencia de la Corte Constitucional Colombiana, encaminadas a regular la protección ambiental, teniendo como eje principal el tema de los recursos hídricos.

Para ello se desarrollarán conceptos como 'constitución ecológica', 'desarrollo sostenible' y 'acceso al servicio de agua potable'. Adicionalmente, se pretende concluir si las diferentes disposiciones legales existentes en la legislación colombiana son suficientes para hacer frente a la crisis ambiental y especialmente a la pérdida de recursos hídricos superficiales que afecta el acceso del líquido para el consumo humano

\section{DESARROLLO LEGAL EN COLOMBIA SOBRE LA PROTECCIÓN DEL MEDIO AMBIENTE Y LOS RECURSOS HÍDRICOS}

En Colombia y el Huila, son claras y preocupantes las consecuencias del cambio climático y la escasez del agua

Yopal, Neiva, Maicao, Santa Martha, Buga, Palmira, entre otras, siendo la mayor fuente de abastecimiento las aguas superficiales como ríos, quebradas, caños, nacederos, las cuales surten de agua de esas 316 a 265 cabeceras municipales, encontrándose su gran mayoría (224) en la región del Magdalena y el Cauca, tal como lo muestran las siguientes gráficas extraídas del estudio en mención:

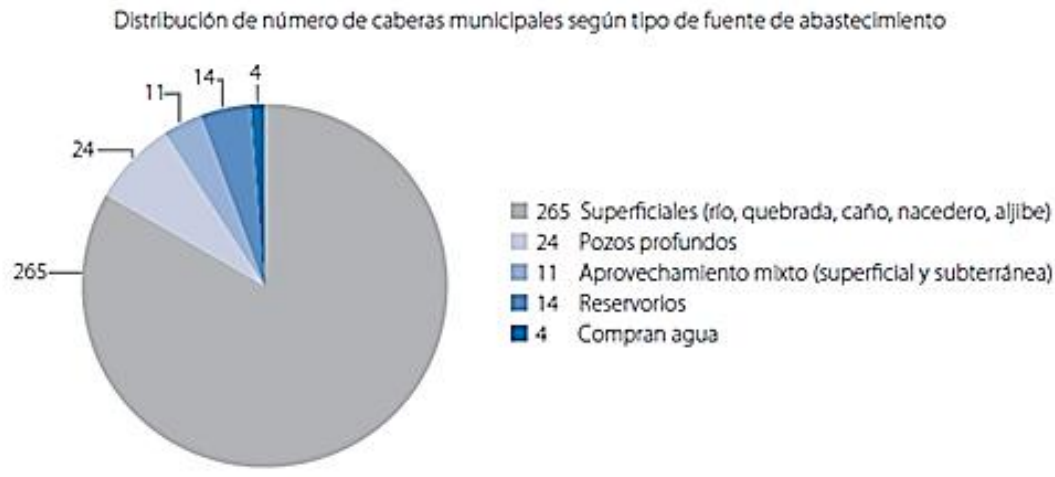


Grafica No. 1 - Fuentes de Abastecimiento en las cabeceras municipales reportadas en situación de desabastecimiento

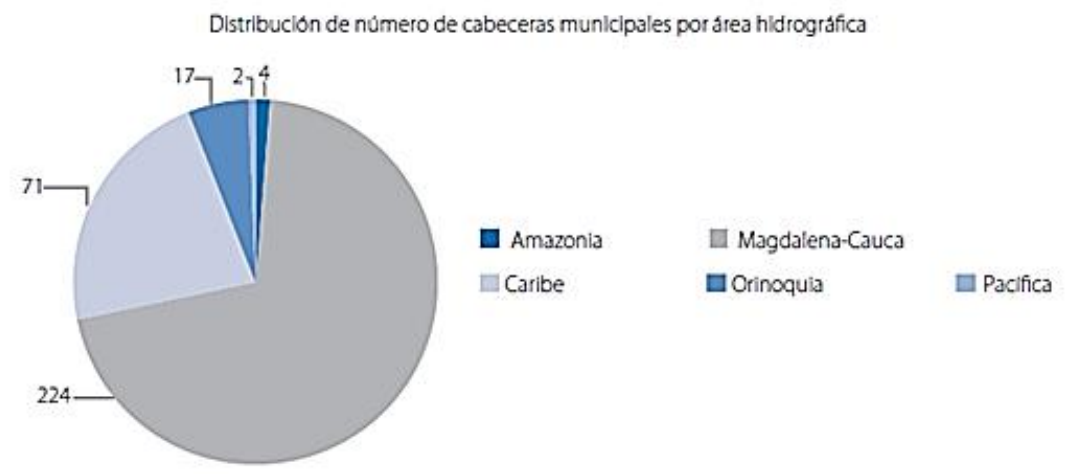

Grafica No. 2. Distribución de las cabeceras municipales identificadas con condiciones de desabastecimiento, por área hidrográfica.

No hay que olvidar que a lo largo de la existencia el ser humano siempre ha tenido la capacidad de alterar las condiciones de la naturaleza. Esta situación aumentó en gran medida a partir de la Revolución Industrial del siglo XVIII al XIX, período durante el cual se dinamizó la producción agrícola e industrial, y los desarrollos científicos y tecnológicos, afectando de igual manera los recursos naturales, generando con esta situación una preocupación en materia internacional por el deterioro del medio ambiente, en especial en 1972 con la Declaración de Estocolmo, donde se incluyó el "medio ambiente" dentro de la agenda internacional.

Por su parte, en 1977 en Mar del Plata (Argentina), se realizó un evento histórico en donde se estableció como parte del plan de acción la evaluación de los recursos hídricos, la eficiencia en la utilización del agua y la importancia de las políticas.

Así mismo, en 1982 en Nairobi (Kenia), se intentó convertir la Conferencia de la Organización de las Naciones Unidas (ONU) en la Cumbre de la Tierra, siendo afectada de manera negativa por múltiples desacuerdos y la situación dominante de la Guerra Fría, llegándose a firmar en 1985 el Convenio de
Viena en el que se aprobó la "Protección de la Capa de Ozono".

En 1987, mediante el Protocolo de Montreal se acordó el control de Clorofluorocarbono (CFC), sustancia química que destruía la capa de ozono (Díaz-Pulido, 2009). Posterior a este año aparecieron en materia internacional importantes acuerdos como el Protocolo de Kioto, aprobado en la Convención Marco de Naciones Unidas sobre Cambio Climático, el cual fue firmado por 155 Estados y ratificado en Colombia mediante la Ley 164 de 1994, redefiniéndose el concepto de desarrollo sostenible en la Asamblea General de las Naciones Unidas en el año 2000, estableciéndose sus 17 objetivos en la Cumbre de Desarrollo Sostenible celebrada el 25 y 27 de septiembre del 2015 , en donde se resaltó que aquel desarrollo sería: “...capaz de satisfacer las necesidades del presente sin comprometer la capacidad de las futuras generaciones para satisfacer sus propias necesidades" (Naciones Unidas, 2015, p. 1). 
Todos estos avances $\mathrm{y}$ al mismo tiempo afectaciones al medio ambiente, trajeron consigo que desde el siglo XIX se implementara en Colombia el Código Civil Colombiano mediante la Ley 57 de 1887, determinando que "los ríos y todas las aguas que corren por cauces naturales son bienes de la Unión, de uso público en los respectivos territorios" (L. 57/1887, Art. 677). Aparece así la gestión del recurso hídrico y el concepto de ordenación de cuencas hidrográficas con el Decreto 1381 de 1940, en donde se avistan los primeros lineamientos explícitos de política para el manejo del agua (MinAmbiente, 2014). Luego, con la creación del Instituto Nacional de los Recursos Naturales Renovables y del AmbienteINDERENA en 1968, se comenzó a enfatizar en el desarrollo de normas para el manejo, uso y aprovechamiento del recurso hídrico.

Sin embargo, fue concretamente con la Ley 4 de 1951, en donde se comenzó a proteger los recursos hídricos al declararse de utilidad pública la zona forestal aledaña al Río Otún y sus afluentes en jurisdicción de Pereira y Santa Rosa (Caldas); área que se ordenó para ser destinada únicamente a la repoblación forestal o la formación de bosques industriales. Ocho años más tarde, con la Ley 2 de 1959, se declararon 7 áreas de reserva forestal tendientes a la protección de los suelos, las aguas y la vida silvestre, denominando a las nuevas áreas como "zonas forestales protectoras" y "bosques de interés general".

Posteriormente, la Ley 23 de 1973, estableció por primera vez en el país una política ambiental que, siguiendo las orientaciones de la Declaración de Estocolmo de 1972, define las circunstancias de degradación ambiental, las competencias de las autoridades públicas para el control y prevención de la contaminación y la obligación de las personas de cuidar del medio ambiente (ValenciaHernández, 2007).

El Decreto-Ley 2811 de 1974, por el cual se expidió el Código Nacional de los Recursos Naturales Renovables y de Protección al Medio Ambiente, norma de vital importancia, acogió los principios de la Convención de Estocolmo de 1972 que, en palabras de Agualimpia-Duabily y Méndez
(2006), establece tres aspectos básicos en la gestión del recurso hídrico:

1. Declaró la propiedad pública de los recursos hídricos y la necesidad de solicitar una concesión del agua para poder hacer uso del mismo.

2. Definió el orden de prioridad para el uso del recurso hídrico: consumo humano, preservación de flora y fauna, agricultura, uso pecuario, recreación, uso industrial y transporte.

3. Introdujo el uso de herramientas económicas para el control de la contaminación (tasas retributivas) y la preservación del recurso hídrico (tasas por uso del agua) (p. 288)

Con el Decreto Reglamentario 1449 de 1977, se definieron obligaciones a los propietarios sobre conservación, protección y aprovechamiento de las aguas, y al año siguiente con el Decreto $1541 \mathrm{de}$ 1978, se reglamentó el Código Nacional de los Recursos Naturales Renovables y de Protección al Medio Ambiente (L. 2811/1974). Estas últimas normas actualmente se encuentran vigentes y se suman a la actual Constitución Política y al Código Civil en materia de regulación sobre las aguas no marítimas y continentales.

Es de suma importancia, para el ordenamiento jurídico colombiano, el Decreto 1541 de 1978, en atención a que regula la propiedad privada respecto al dominio sobre las aguas, cauces y riberas, así como la extinción del dominio privado de las aguas, del modo de adquirir el derecho al uso de las aguas y sus cauces, y respecto a la explotación y ocupación de las playas, cauces y lechos, el régimen de ciertas categorías especiales de aguas y, algo muy importante, un título especial en relación a la conservación y preservación de las aguas y sus cauces, estableciendo para el efecto un régimen de prohibiciones y sanciones.

Por su parte, el Decreto 2857 de 1981 reglamentó las cuencas hidrográficas; el Decreto 1594 de 1984 definió los límites permisibles para el vertimiento o descarga de residuos líquidos a un cuerpo de agua o alcantarillado sanitario y la Ley 79 de 1986 
declaró áreas de reserva forestal protectora para la conservación y preservación del agua.

Con la Constitución Política de Colombia de 1991, la protección al medio ambiente se materializó en relación a lo que llamaron "los derechos colectivos", estableciéndose como tal el derecho a un ambiente sano, sin dejar de lado "el carácter limitado del derecho de propiedad dado por los derechos colectivos" (Clavijo-Prada, 2015, p. 45).

Por tanto, es deber del Estado Colombiano proteger la diversidad e integridad del ambiente, conservar las zonas de especial importancia ecológica y prevenir-controlar los factores de deterioro ambiental. En ese orden de ideas, el artículo 356 de la Carta Política de Colombia previó la necesidad de destinar y priorizar los recursos del "Sistema General de Participaciones" de los municipios, para financiar los servicios públicos domiciliarios de agua potable y saneamiento básico con el respectivo seguimiento a cargo de Gobierno Nacional.

Así mismo, Rincón-Córdoba (2012) ha señalado:

Aunque esta obligación vincula a todos los poderes públicos, la Administración desempeña un papel preponderante en la consecución de este objetivo, pues es ella, en el ejercicio de sus competencias y en la relación directa que entabla con los administrados, la que tiene los instrumentos adecuados para la protección y defensa de los recursos naturales (p. 92).

Es así como del análisis de la Constitución Política de Colombia se tiene alrededor de 34 artículos o disposiciones que conforman o dan cuerpo a lo que la Corte Constitucional ha llamado "Constitución Ecológica", a partir de los cuales se ha dado la protección al medio ambiente en material legal y jurisprudencial.

Conforme a la normatividad constitucional referenciada, y a los compromisos adquiridos en la Cumbre de Rio, se expidió la Ley 99 de 1993, la cual creó el Ministerio del Medio Ambiente (hoy Ministerio de Ambiente y Desarrollo Sostenible), estableciendo para el manejo ambiental del país el Sistema Nacional Ambiental (SINA), entre otras disposiciones, destacándose dentro de sus principios generales en su artículo primero los siguientes:

$(\ldots)$

4. Las zonas de páramos, subpáramos, los nacimientos de agua y las zonas de recarga de acuíferos serán objeto de protección especial.

5. En la utilización de los recursos hídricos, el consumo humano tendrá prioridad sobre cualquier otro uso.

11. Los estudios de impacto ambiental serán el instrumento básico para la toma de decisiones, con respecto a la construcción de obras o actividades que afecten significativamente el medio ambiente natural o artificial (L. 99/1993, Art. 1).

Así mismo, la Ley 99 de 1993 estableció:

Declárense de interés público las que surten de agua los acueductos municipales y distritales. Los departamentos y municipios dedicarán durante quince años un porcentaje no inferior al $1 \%$ de sus ingresos, de tal forma que antes de concluido tal período, haya adquirido dichas zonas. La administración de estas zonas corresponderá al respectivo distrito o municipio en forma conjunta con la respectiva Corporación Autónoma Regional y con la opcional participación de la sociedad civil (L. 99/1993, Art. 111).

Posteriormente se expidió la Ley 165 de 1994, por medio de la cual se aprobó el "Convenio sobre la Diversidad Biológica", en donde se estableció:

Artículo 6: Cada parte contratante, con arreglo a sus condiciones y capacidades particulares:

a) Elaborará estrategias, planes o programas nacionales para la conservación y la utilización sostenible de la diversidad biológica o adaptará para ese fin las estrategias, planes o programas existentes, que habrán de reflejar, entre otras cosas, las medidas establecidas en el presente Convenio que sean pertinentes 
para la Parte Contratante interesada; y b) Integrará, en la medida de lo posible y según proceda, la conservación y la utilización sostenible de la diversidad biológica en los planes, programas y políticas sectoriales o intersectoriales.

Por otra parte, como norma importante se destaca la Ley 388 de 1997, reglamentada por los Decretos 211 de 1997, 540 de 1998, 879 de 1998, 1420 de 1998, 1052 de 1998, 1504 de 1998, 1507 de 1998, 1599 de 1998, 150 de 1999, 297 de 1999, 1198 de 1999, 1686 de 2000, la cual dio autonomía a las entidades territoriales, a través de la descentralización del Estado, para la conservación de los recursos naturales, teniendo a la mano los respectivos estudios técnicos; instrumentos indispensable para la toma de decisiones, más específicamente hacia los planes de ordenamiento territorial y las agendas ambientales.

Respecto a lo rural, con el Decreto 1729 del año 2002 se reglamentaron apartes del Código Nacional de los Recursos Naturales Renovables y de Protección al Medio Ambiente y de la Ley 99 de 1993 respecto a la ordenación de las cuencas hidrográficas, así como se involucró el concepto de uso y manejo sostenible de los recursos naturales renovables.

El artículo 111 de la Ley 99 de 1993 fue modificado por el Artículo 106 de la Ley 1151 del 2007, eliminándose el límite temporal de los 15 años, estableciendo esta obligación a cargo de los departamentos y municipios de destinar el $1 \%$ de sus ingresos corrientes para la adquisición y mantenimiento de dichas zonas, agregando que este valor adicionalmente podría ser destinado para financiar esquemas de pago por servicios ambientales incluyendo a la Unidad Administrativa Especial del Sistema de Parques Nacionales Naturales como autoridad competente para la administración de dichas zonas cuando corresponda.

Ya en el año 2010, el Ministerio de Ambiente, Vivienda y Desarrollo Territorial (hoy Ministerio de Ambiente y Desarrollo Sostenible), expidió la "Política Nacional para la Gestión Integral del Recurso Hídrico", definiendo a la cuenca hidrográfica como una unidad espacial de análisis y de gestión, en donde el líquido vital se entrelaza con los demás recursos naturales renovables y ecosistemas estratégicos, así como los actores clave para la gestión integrada del recurso hídrico (Autoridades Ambientales, usuarios, entes territoriales y demás entidades tanto públicas como privadas que actúan en la cuenca).

Posteriormente, en la Ley 1450 del 2011, a través de la cual se expidió el Plan Nacional de Desarrollo 2010-2014, se resaltó la inclusión de los acueductos regionales. De igual forma, se aclaró que el $1 \%$ de los ingresos corrientes de cada ente territorial debería ser destinado prioritariamente a la adquisición y mantenimiento de dichas zonas, estableciendo la obligación de definir las áreas prioritarias a ser adquiridas o hacia donde se deben implementar los esquemas por pagos de servicios ambientales en cabeza de las autoridades ambientales conforme a la reglamentación del Ministerio de Ambiente, Vivienda y Desarrollo Territorial.

Así mismo, la referida ley estableció:

(...) en el marco de sus competencias, corresponde a las Corporaciones Autónomas Regionales y de Desarrollo Sostenible la formulación de los Planes de Ordenación y Manejo de las Cuencas Hidrográficas conforme a los criterios establecidos por el Gobierno Nacional en cabeza del Ministerio de Ambiente, Vivienda y Desarrollo Territorial o quien haga sus veces (L. 1450/2011, Art. 215).

Luego se expidió el Decreto 1640 de 2012, por medio del cual se reglamentaron los instrumentos para la planificación, ordenación y manejo de las cuencas hidrográficas y acuíferos, y se dictaron otras disposiciones. Esta reglamentación estableció la nueva estructura de planificación, ordenación y manejo de las cuencas hidrográficas del país, permitiendo una mayor claridad en el nivel de gestión de las mismas por parte de las autoridades ambientales competentes y las diferentes entidades $\mathrm{y}$ actores responsables de su formulación e implementación. Adicionalmente, se expidió la Resolución 509 del 2013 por la cual se definieron 
los lineamientos para la conformación de los consejos de cuenca y su participación en las fases del plan de ordenación de la cuenca, entre otras disposiciones.

Ahora bien, el Decreto 953 de 2013, el cual reglamentó íntegramente el artículo 111 de la Ley 99 de 1993, estableció las directrices para la adquisición y mantenimiento de las áreas de importancia estratégica, destacándose en esta oportunidad su objeto, ámbito de aplicación, definiciones, esquemas de pago por servicios ambientales, entre otros aspectos de suma importancia como son los criterios que se deben tener en cuenta para la selección de predios, garantizando que la adquisición se haga en zonas que realmente sean de impacto para la conservación de las fuentes hídricas que surten de agua los acueductos municipales y reafirmando la importancia de su compra y de la realización de actividades en los predios adquiridos por las entidades territoriales para la conservación y recuperación de los ecosistemas presentes en los mismos.

Por otra parte, en su momento también se pronunció la Contraloría General de la República, a través de las Circulares 008 y 009 del año 2008. En la primera, le recordó a los gobernadores y alcaldes del país la obligación de destinar las partidas presupuestales para delimitar y adquirir las áreas para la conservación de los recursos hídricos en los términos de la Ley 99 de 1993 y la Ley 1151 del 2007, por cuanto, de acuerdo a los indicadores de la época, los recursos hídricos se venían deteriorando progresivamente; y respecto a la segunda, le recordó también a las corporaciones autónomas regionales y a las corporaciones para el desarrollo sostenible y autoridades ambientales urbanas del país, participar en el proceso para la adquisición de áreas de interés para acueductos municipales.

Así mismo, se encuentra que el Ministerio de Ambiente, Vivienda y Desarrollo Territorial (hoy Ministerio de Ambiente y Desarrollo Sostenible), en el año 2010, emitió la "Política Nacional para la Gestión Integral del Recurso Hídrico" en donde se establecieron los objetivos, estrategias, metas, indicadores y líneas de acción estratégica para el manejo del recurso hídrico en el país en un horizonte de 12 años (MinAmbiente, 2010).

Para mayor claridad, a continuación se trae la figura presentada por el Ministerio de Medio Ambiente y Desarrollo Sostenible en el año 2014 en la "Guía técnica para la formulación de los Planes de Ordenación y Manejo de Cuencas Hidrográficas POMCAS" (MinAmbiente, 2014), e donde, con mayor claridad, se puede determinar el marco normativo que existe en Colombia para la ordenación y manejo de cuencas hidrográficas:

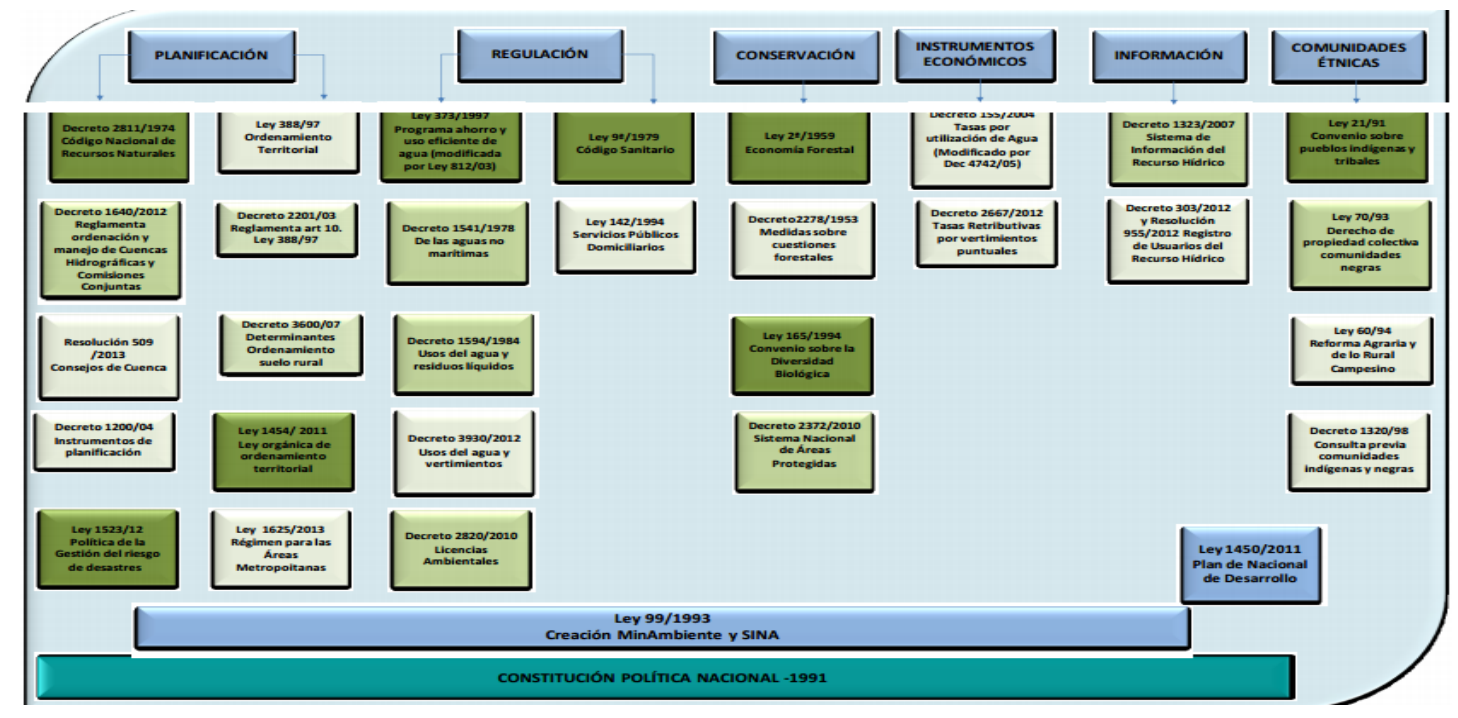


Gráfica No. 3: Marco normativo respecto a la ordenación y manejo de cuencas hidrográficas en Colombia.

Otro aspecto importante a resaltar es que en materia institucional, en la gestión del recurso hídrico en Colombia, el primer cambio importante se dio desde el año 1968 con la creación del Instituto Nacional de los Recursos Naturales Renovables y del Ambiente INDERENA, entidad que se encargó de las concesiones de agua y manejo del recurso hídrico a nivel nacional.

En 1993 se creó el Ministerio del Medio Ambiente, el cual pasó a llamarse en el año 2003 Ministerio de Ambiente, Vivienda y Desarrollo Territorial (hoy Ministerio de Ambiente y Desarrollo Sostenible), quedando como máxima autoridad en materia del manejo del recurso hídrico, estableciéndose a su cargo dentro de sus importantes funciones la de formular, gestionar y coordinar las políticas, regulaciones y programas en agua potable, la gestión del recurso hídrico, entre otras.

Con la creación de este Ministerio, en el año 1993, se crearon a su vez 11 Corporaciones Autónomas Regionales (CAR) adicionales a las 15 que ya existían, y adicionalmente 7 como corporaciones de desarrollo sostenible, las cuales se encargarían de gestionar el agua a nivel local, a través de las siguientes funciones:

1. Distribuir el recurso del agua a los diferentes usuarios.

2. Controlar las fuentes de contaminación puntual y difusa del recurso hídrico.

3. Formular los planes de ordenación y manejo de cuencas hidrográficas y

4. Diseñar programas para proteger el medio ambiente.

Pero no solamente estas instituciones tienen que ver con la gestión de los recursos hídricos, son muchas más; por mencionar algunas, a través de los ministerios y demás entidades, las cuales han influido de manera directa o indirecta en la gestión del recurso hídrico. Por ejemplo, desde los años 50 hasta mediados de los 80 , el suministro de servicios en Colombia se hacía centralizadamente a través del Instituto de Fomento Municipal INSFOPAL, el cual se encargaba de atender las zonas urbanas con una población mayor a 2.500 habitantes, mientras las zonas rurales eran competencia del Programa de Saneamiento Básico Rural liderado por el Instituto Nacional de Salud (INS). Estas dos entidades se liquidan, entregándose a los municipios la responsabilidad de la prestación de los servicios del agua y saneamiento, descentralización que se hace aún más marcada con la Constitución de 1991 y la Ley 142 de 1994, conocida como de Servicios Públicos Domiciliarios (Rojas, 2011).

\section{DESARROLLO JURISPRUDENCIAL DE LA CORTE CONSTITUCIONAL COLOMBIANA SOBRE PROTECCIÓN DEL MEDIO AMBIENTE Y LOS RECURSOS HÍDRICOS}

La Corte Constitucional en su ejercicio esencial de guardia de la integridad y supremacía de la Constitución Política de Colombia, ha proferido desde 1992 varias sentencias en desarrollo a los postulados de la Carta Política sobre el medio ambiente y la protección de recursos hídricos estrechamente ligados al concepto de desarrollo sostenible desde la perspectiva de una "Constitución Ecológica".

\subsection{Protección del Medio Ambiente, "Constitución Ecológica" y Desarrollo Sostenible}

Desde 1992, en la Sentencia T-411, al resolver un caso donde se reflejaba el conflicto de intereses entre el derecho al trabajo, la propiedad privada y la libertad de empresa versus el derecho a gozar de una calidad de vida expresada en un ambiente sano y ecológicamente equilibrado, la Corte Constitucional introdujo el concepto de "Constitución Ecológica" para resaltar la importancia de proteger jurídicamente el medio ambiente como un derecho fundamental que garantiza la vida y a la vez impone límites a la actividad económica.

En aquella ocasión la Corte también se preocupó por resaltar los problemas ambientales y la contaminación de los recursos hídricos, haciendo un llamado enérgico a tomar conciencia ecológica, manifestando: 
Para esta Sala de Revisión, la protección al ambiente no es un "amor platónico hacia la madre naturaleza", sino la respuesta a un problema que de seguirse agravando al ritmo presente, acabaría planteando una auténtica cuestión de vida o muerte: la contaminación de los ríos y mares, la progresiva desaparición de la fauna y la flora, la conversión en irrespirable de la atmósfera de muchas grandes ciudades por la polución, la desaparición de la capa de ozono, el efecto invernadero, el ruido, la deforestación, el aumento de la erosión, el uso de productos químicos, los desechos industriales, la lluvia ácida, los melones nucleares, el empobrecimiento de los bancos genéticos del planeta, etc., son cuestiones tan vitales que merecen una decisión firme y unánime de la población mundial. Al fin y al cabo el patrimonio natural de un país, al igual que ocurre con el histórico - artístico, pertenece a las personas que en él viven, pero también a las generaciones venideras, puesto que estamos en la obligación y el desafío de entregar el legado que hemos recibido en condiciones óptimas a nuestros descendientes (CConst, T411/1992).

En la Sentencia C-058 de 1994, la Corte Constitucional continuó reconociendo que la protección del medio ambiente juega un papel esencial en el ordenamiento jurídico y afianzó el concepto de "Constitución Ecológica", como todas aquellas disposiciones contenidas en la Constitución Política de 1991 que regulan la relación de la sociedad con la naturaleza y que buscan proteger el medio ambiente.

En este sentido estableció entonces que la "Constitución Ecológica" tiene una triple dimensión: i) la protección al medio ambiente es un principio que irradia todo el orden jurídico, ya que es deber del Estado proteger los recursos naturales, entre los que se encuentra por supuesto el agua, ii) aparece como el derecho de todas las personas a gozar de un ambiente sano, y iii) finalmente, de la Constitución Ecológica derivan un conjunto de obligaciones impuestas a las autoridades y a los particulares; es decir, se refuerza el concepto de protección ambiental que trajo consigo la necesidad de hacer un uso racional de los recursos naturales, comenzando una labor normativa en un sentido más conservacionista (Mondéjar-Pedreño, 2015).

En el análisis de constitucionalidad del Decreto Ley 23 de 1973, "por la cual se conceden facultades extraordinarias al presidente de la República para expedir el Código de Recursos Naturales y de Protección al Medio Ambiente y se dictan otras disposiciones" y algunos artículos de la Ley 142 de 1994, la Corte Constitucional precisó que el concepto de Constitución Ecológica implica para las autoridades y particulares un número de obligaciones, y que es tal la importancia del medio ambiente en la Constitución que implica para el Estado, en materia ecológica, "unos deberes calificados de protección".

En otro pronunciamiento de exequibilidad sobre algunos apartes de la Ley 1333 de 2009 "Por la cual se establece el procedimiento sancionatorio ambiental y se dictan otras disposiciones", el máximo tribunal constitucional de Colombia nuevamente resalta el alcance de la Constitución Ecológica dirigida a regular la relación armónica entre el desarrollo de la sociedad y la naturaleza buscando proteger el medio ambiente ante la intervención negativa humana. En esta oportunidad se resaltó:

Es sabido que la mayor afectación del medio ambiente la constituyen causas antropogénicas, es decir, aquellas derivadas de la actividad humana tendentes a la satisfacción de sus necesidades. Estas actividades, desarrolladas especialmente desde el siglo anterior, cuando los procesos industrializados y la población mundial se aceleraron tan abruptamente, ejercidos sin un criterio de sostenibilidad, generan un impacto negativo sobre los recursos naturales y el ecosistema global. Dichos impactos 
sobre el medio ambiente son evidentes: polución terrestre, aérea y marina, lluvia ácida, agotamiento de la capa de ozono, calentamiento global, extinción de especies de fauna y flora, degradación de hábitats, deforestación, entre muchos otros (CConst, C- 595/2010).

En la Sentencia T-608 de 2011, la Corte Constitucional hace un interesante análisis de la evolución normativa en Colombia dirigida a proteger el medio ambiente, advirtiendo que en un principio se limitaba a regular las relaciones entre personas llevando inmerso la regulación del uso de los recursos naturales como parte de la propiedad, es decir que existía una concepción utilitarista del medio ambiente en beneficio del desarrollo humano sin limitación alguna. Sin embargo, a partir de la Declaración de Estocolmo de 1972 esta visión fue transformándose hasta entenderse que los recursos naturales eran limitados y por ende su conservación era de interés para preservar la humanidad y, por tanto, dicha función le correspondía a los particulares y al Estado.

Continúa la Corte haciendo el recorrido hasta llegar a la Constitución Política de 1991, a partir de la cual la perspectiva del medio ambiente sigue su metamorfosis, erigiendo a derecho el goce de un ambiente sano. Asimismo, se estableció que en cabeza del Estado está el deber y facultad de prevenir y controlar los factores de deterioro del medio ambiente, garantizar su desarrollo sostenible y garantizar su conservación, restauración y sustitución, a partir de la existencia de competencias normativas concurrentes entre el poder central y las autoridades locales, donde también participan los particulares, situación que solo se puede dar aplicando lo que la Corte definió como el "principio de rigor subsidiario" establecido en el artículo 288 de la Constitución, recogido por el artículo 63 de la Ley 99 de 1993, y definido entre otros doctrinantes por CifuentesSandoval (2013), así:

Instrumento fundado bajo el esquema de la República Unitaria y de la descentralización administrativa y territorial, que permite el ejercicio de aquellas competencias que concurren en cabeza de varias instituciones estatales, y que respetando la autonomía local y la estructura jerárquica del sistema, reglamenta y adapta la normatividad ambiental básica sin hacerla menos rígida que aquella que proviene de las autoridades ubicadas en un nivel más alto en la administración ambiental (p. 347).

Con base en lo anterior, la Corte Constitucional denominó a la Constitución Política de Colombia de 1991 como "Constitución Ecológica" o "Constitución Verde", con el propósito de regular la protección al medio ambiente, entre esos los recursos hídricos, que de acuerdo a MarulandaGarcía y García-González (2013) "reafirma la relación directa existente entre los derechos colectivos y las herramientas que permiten al Estado garantizar la efectiva participación ciudadana en las decisiones que tienen que ver con el medio ambiente" (p. 185).

Por otro lado, la Corte Constitucional ha tejido la jurisprudencia sobre el medio ambiente y los recursos naturales desde la óptica del desarrollo sostenible, como punto de equilibrio entre su explotación y conservación. Es así como en la Sentencia C- 058 de 1994, la Corte considera "que muchas de las obligaciones ecológicas impuestas por la Carta de 1991 adquieren mayor significado a la luz de esta idea de desarrollo sostenible”.

En ese orden, el desarrollo sostenible debe permitir mejorar la calidad de vida de las personas en redundancia también del bienestar común pero sin exceder la capacidad de carga de los recursos naturales que sirven de base biológica y material a la actividad productiva.

Así mismo, el máximo Tribunal Constitucional señaló:

Conforme a las normas de la Carta el medio ambiente es un derecho constitucional fundamental para todos los individuos de la especie humana y el Estado está obligado a velar por su conservación y debida protección, procurando que el desarrollo económico y social sea compatible con las políticas que 
buscan salvaguardar las riquezas naturales de la Nación (CConst, C-671/2001).

Continúa la Corte resaltando en la sentencia referida que, dentro del marco legal, la Carta dispone varias normas relativas a la ecología y el medio ambiente, entre las cuales se resaltan los artículos 79 y 80 , que consagran el derecho de todas las personas a gozar de un ambiente sano, haciendo participes a la comunidad en la decisiones que puedan afectarlos y el deber estatal de proteger la diversidad e integridad del ambiente, también respecto de la planificación en el manejo y aprovechamiento de los recursos naturales para garantizar su desarrollo sostenible, su conservación, restauración o sustitución.

En esa misma línea jurisprudencial, en la Sentencia C-293 de 2002, cuando la Corte se pronunció sobre la demanda de inconstitucionalidad de los artículos 1 , numeral 6; 85, numeral 2 y parágrafo 3 , de la Ley 99 de 1993, sostuvo que la explotación de los recursos naturales en el marco de una actividad económica no puede quebrantar el derecho de los colombianos a disfrutar de un medio ambiente sano, así sea importante la actividad a desarrollar para la dinamización o crecimiento de la economía.

En decisión más reciente, la Sentencia C-094 de 2015, mediante la cual declaró inexequible el Decreto 1111 de 1952, "por el cual se provee a la conservación y mejor aprovechamiento de las aguas del Lago de Tota y se reconoce el carácter de utilidad pública a unas obras", la Corte resumió la jurisprudencia constitucional sobre el alcance del principio de desarrollo sostenible, al señalar que:

(i) el concepto de desarrollo sostenible debe ser entendido como una categoría síntesis que pretende armonizar el desarrollo económico y la protección del ambiente; (ii) este principio y el deber del Estado de planificar el manejo de los recursos naturales son la expresión del principio de solidaridad intergeneracional que consiste en satisfacer las necesidades de las generaciones presentes pero sin comprometer la capacidad de las generaciones futuras para satisfacer las propias; (iii) la responsabilidad del Estado de planificar y aprovechar los recursos naturales de forma tal que se logre un desarrollo sostenible requiere el desarrollo de una política de la planificación ambiental que tenga cobertura nacional; (iv) la libertad de la actividad económica que desarrollan los particulares está limitada por la necesidad de preservar y conservar un ambiente sano (CConst, 094/2015).

Por su parte, en la Sentencia C-449 de 2015, la Corte estableció que la legislación expedida y la jurisprudencia constitucional sobre la defensa al medio natural y el entorno ecológico, han partido de un desarrollo histórico y líneas de pensamiento que han desembocado en la existencia de diversos enfoques jurídicos que vienen a concretarse en visiones: i) antropocéntricas, ii) biocéntricas y iii) ecocéntricas, entre otras. Resaltó, además, al desarrollo sostenible como un principio rector del medio ambiente que asegura el desarrollo económico y social para satisfacer las necesidades previendo que las futuras generaciones también tengan la oportunidad de hacerlo.

\subsection{Protección de los recursos hídricos y acceso al agua potable}

Aunque la protección al medio ambiente lleva implícito la protección de los recursos hídricos, la Corte Constitucional le ha dado un capítulo especial al tema del agua; la jurisprudencia ha resaltado las bondades jurídicas de proteger este recurso natural para que el Estado cumpla su obligación de suministrar el servicio de agua potable y saneamiento básico, según el artículo 366 de la Constitución Política de Colombia de 1991.

En un principio, la Corte Constitucional se ocupa de exaltar las facultades del agua como generadora de vida y su vital importancia para la especie humana. En la Sentencia T-244 de 1994, por ejemplo, la Corte ordenó la construcción de un acueducto veredal, accediendo así a proteger los derechos a la vida y a la salud de los habitantes de la zona. Con posterioridad, expresó en relación con la importancia del agua: 
El agua siempre ha estado en el corazón de los hombres y en la base de las civilizaciones. Se puede pasar varios días sin comer, pero sin beber es imposible sobrevivir unos pocos. En el cuerpo humano el 96\% de la linfa es agua, hay el $80 \%$ en la sangre, las dos terceras partes de los tejidos también contienen agua. Un proverbio usbeko enseña: que no es rico quien posee tierra sino quien tiene agua (CConst, T-523/1994).

En las consideraciones de la Sentencia T-418 de 2010 , en referencia a un caso puntual sobre acceso de agua potable de unos habitantes del área rural del municipio de Arbeláez Cundinamarca, la Corte trajo a colación algunos datos alarmantes del Comité de Derechos Económicos y Culturales (Observación General N ${ }^{\circ} 15$ del 2002), donde advertían que para el año 2002: 1.000 millones de personas carecían de un suministro suficiente de agua y varios miles de millones no tenían acceso a servicio de saneamiento, constituyéndose tal situación en la principal causa de contaminación del agua, sumado al deterioro de los recursos hídricos.

Así mismo, en Sentencias T-410 de 2003 y T-270 de 2007, la Corte Constitucional no solo amparó el agua como un bien vital para la subsistencia de cada ser humano, sino también se protegió el derecho colectivo que tienen las comunidades de recibir por parte del Estado un abastecimiento seguro y de calidad, independiente de la forma en que se suministra el recurso hídrico en mención.

En la Sentencia C-220 de 2011, a través de la cual la Corte Constitucional declaró la exequibilidad del parágrafo del Artículo 43 de la Ley 99 de 1993, fue precisa en señalar la obligación que tiene el Estado de proteger los recursos hídricos y recordó que el agua es patrimonio de la Nación, un bien de uso público y un derecho fundamental. En estas condiciones, la Constitución Política de 1991 "protege el ambiente y, en particular, el agua como fuente de vida". También, expuso el papel garante que tiene el Estado en la administración y uso adecuado del recurso hídrico del país que demanda un rol complejo en su ejercicio, motivo por la cual expresó:
La Constitución obliga a diseñar múltiples estrategias dirigidas a garantizar el uso racional del agua, las cuales deben ser acompañadas del debido soporte técnico. Esa obligación se ha concretado en la creación de instituciones encargas de adoptar políticas ambientales y de buena utilización del agua, y de seguir, vigilar y controlar el cumplimiento de tales políticas (CConst, C-220/2011).

En esta misma dirección, la Corte Constitucional se había pronunciado en la Sentencia T-616 de 2010, al afirmar que las entidades deben adoptar todas las medidas tendientes a salvaguardar el mínimo componente del derecho al agua y, respecto del goce pleno del mismo, tienen la obligación constitucional de avanzar constantemente, mediante el diseño de políticas públicas específicas y la utilización del máximo de recursos posibles.

La Corte, en la Sentencia C-094 de 2015, en lo que respecta a la protección de recursos hídricos, hizo un breve recuento de algunas disposiciones internacionales adoptadas por Colombia e introducidas a la Constitución Política de 1991, en la cuales los estados han reconocido la relevancia de proteger los recursos naturales de la tierra, incluido el agua, "mediante la planificación sistemática orientada a satisfacer las necesidades esenciales, y a promover una distribución eficiente y equitativa de los recursos hídricos, la garantía de los ecosistemas y el ciclo hidrológico". En ese orden expresó que la jurisprudencia de la misma Corte ha hecho hincapié sobre la existencia de las obligaciones del Estado para proteger los recursos hídricos en aras de garantizar el derecho al agua de los habitantes del país.

En otras sentencias de tutela, como la 080 de 2015 y 445 de 2016, la Corte ha recogido los postulados constitucionales en defensa de los recursos hídricos y su importancia para proveer de agua a las personas, como derecho autónomo y en conexidad con el derecho fundamental a la vida y la salud, exigiendo de las autoridades políticas y acciones de conservación, reparación y prevención, señalando al respecto:

Así las cosas, el deber de prevenir y restaurar los ecosistemas intervenidos por 
el hombre, trae consigo la obligación de identificar cuáles son los lugares más estratégicos por sus características ecológicas y naturales, para así propender por su correcto tratamiento hasta llegar o aproximarse a un punto de impacto ambiental cero (CConst, T-445/2016).

La visión sobre la protección del agua para preservar la vida del ser humano y suplir las necesidades del líquido de las futuras generaciones, puede sufrir un cambio significativo a raíz de la Sentencia T-622 de 2016 de la Corte Constitucional. En las consideraciones, la Corte expuso el concepto, desarrollo y alcance del Estado Social de Derecho, recordando la relevancia constitucional que tiene la protección de los ríos, los bosques, el medio ambiente y la biodiversidad; agregó que la explotación de los recursos naturales no puede traducirse en perjuicio o daño al medio ambiente, cuya defensa constituye un objetivo fundamental en el ordenamiento jurídico y para el Estado.

En consecuencia, y ante los daños causados por la minería ilegal, la contaminación, la tala indiscriminada de bosques etc., declaró al río Atrato ubicado en del Departamento de Chocó, como sujeto de derechos y ordenó a las autoridades competentes nacionales, departamentales y locales tomar una serie de medidas correctivas con el fin de evitar su extinción. En esta oportunidad, la Corte hace una reflexión sobre la utilización de los recursos naturales, que bien vale la pena traer a colación de forma taxativa:

De acuerdo con esta interpretación, la especie humana es solo un evento más dentro de una larga cadena evolutiva que ha perdurado por miles de millones de años y, por tanto, de ninguna manera es la dueña de las demás especies, de la biodiversidad ni de los recursos naturales, como tampoco del destino del planeta. En consecuencia, esta teoría concibe la naturaleza como un auténtico sujeto de derechos que deben ser reconocidos por los estados y ejercidos bajo la tutela de sus representantes legales, verbigracia, por las comunidades que la habitan o que tienen una especial relación con ella (CConst, T-622/16).

Es posible entonces observar que en Colombia existe una legislación y un desarrollo jurisprudencial rico en materia ambiental, que no solamente ha asentado un lineamiento legal en torno al tema, sino que ha dispuesto obligaciones concretas y particulares al Estado a través de sus entidades, para la protección de los recursos naturales, entre esos el agua.

\section{CONCLUSIONES}

Es innegable que las condiciones ambientales y climáticas en el planeta tierra han sido sistemáticamente alteradas a causa de la intervención humana. Colombia y, en especial, el Departamento del Huila, no son ajenos a los efectos producidos por el calentamiento global.

El impacto negativo en los recursos naturales, particularmente en el hídrico, hace necesario que el Estado asuma, sin ambages, su rol en defensa del interés público de preservar el patrimonio ecológico. El agua potable, esencial para preservar la vida de los asociados, debe ser garantizada como servicio público a través de los acueductos.

Existe una estrecha relación entre la conservación de los recursos naturales y la prestación de servicio de agua potable; en la medida en que se cumpla la tarea, se garantiza la óptima provisión del líquido para consumo directo o tratado en acueductos.

Tal como lo aseveró la Corte Constitucional en la Sentencia T-445 del 2016, es inequívoco que la protección jurídica del medio ambiente y todos los recursos naturales es hoy una prioridad reconocida universalmente por el Derecho y los Estados, la cual tiene como objetivo principal dar una respuesta determinante a las afectaciones que sufren los ecosistemas. Necesidad que se hace más esencial aún si se tiene como base que la protección de los recursos hídricos "asegura la supervivencia de las generaciones presentes y futuras", condicionando a la vez el ejercicio de ciertos derechos de los asociados, conforme a la función ecológica que debe cumplir la propiedad y obliga a actuar con responsabilidad, dado que la satisfacción de las necesidades del hombre requiere de planificación económica. La protección de los sistemas naturales no debe condicionarse o 
entenderse como medio para garantizar el desarrollo económico y social, sino por el contrario, esta obligación inexcusable "nace del deber de respetar y garantizar los derechos de la Naturaleza también como sujeto autónomo",,CConst, T-445/2016, J. Palacio) es decir, no se debe pretender proteger jurídicamente el medio ambiente obedeciendo a intereses del hombre, sino porque tiene derecho a su propia e independiente desarrollo y supervivencia.

De hecho, han existido esfuerzos desde finales del siglo XIX por crear un marco jurídico entorno a la protección del medio ambiente y los recursos hídricos en intentos de regular situaciones que los afectan pero, paralelo a ello, en el mismo ámbito jurídico se han abierto las puertas a la explotación de los recursos para el aprovechamiento desmedido de los sistemas socio económicos. Instituciones y entidades han sido dotadas jurídicamente de competencias, funciones, estructuras y planes para encargasen de la gestión y conservación del medio ambiente y los recursos naturales.

Aunque las normas se han concentrado en crear la estructura administrativa, la distribución de competencias, responsabilidades y procedimientos legales, hay importantes avances en la lucha contra la contaminación y la conservación de la naturaleza, destacándose además la formulación de nuevos conceptos y la fijación de estándares, apoyados en el desarrollo del derecho internacional.

\section{REFERENCIAS BIBLIOGRÁFICAS}

I. CEPAL (1992). Principios de Dublín. En Solanes, M., y González-Villareal, F. (2010). Recuperado de: https://archivo.cepal.org/pdfs/Waterguide /Tac3s.pdf

II. Cifuentes-Sandoval, G. (2013). Desarrollo Constitucional, Legal y Jurisprudencia del principio de rigor subsidiario. Revista Jurídicas CUC, 9 (1), 345-384. Recuperado el 29 de Septiembre del 2016 de: https://revistascientificas.cuc.edu.co/jurid icascuc/article/view/454/pdf 39

III. Clavijo-Prada, S. (2015). Protección de los ecosistemas estratégicos y desarrollo: un reto para el derecho. Revista Estudios del Derecho, (159), 45. Recuperado el 5 de Octubre del 2016 de: https://doi.org/10.17533/udea.esde.v72n1 $\underline{59 \mathrm{a} 03}$

IV. Díaz-Pulido, A. P., Hernández, N. C., Muñoz-Moreno, D., Olaya-González, W. R., Perilla-Castro, C., Sánchez-Ojeda, F., y Sánchez-González, K. (2009). Desarrollo sostenible y el agua como derecho en Colombia. Revista Estudios Socio-Jurídicos, $\quad 11(1), \quad 84-116$. Recuperado el 15 de abril del 2017 de https://revistas.urosario.edu.co/index.php /sociojuridicos/article/view/53

V. Agualimpia-Duabily, Y. d. C., y Méndez, E. C. (2006). Metodologías para la determinación de los caudales ecológicos en el manejo de los recursos hídricos. Tecnogestión, 3(1), 288. Recuperado el 15 de abril del 2017 de https://revistas.udistrital.edu.co/index.ph p/tecges/article/view/4333/6062

VI. Instituto de Hidrología, Meteorología y Estudios Ambientales - IDEAM. (2014). Estudio Nacional del Agua 2014. Recuperado el 15 de abril del 2017 de: http://documentacion.ideam.gov.co/open biblio/bvirtual/023080/ENA 2014.pdf

VII. Marulanda-García, N., y García-González, J. (2013). Los derechos ambientales frente a 
"otras prioridades". Estudio de un caso emblemático. Revista Jurídicas, 10(1), 181. Recuperado el 10 de Septiembre del 2016

de: http://juridicas.ucaldas.edu.co/downloads /Juridicas10(1)_Completa.pdf

VIII. Mesa-Cuadros, G. (2013). Derechos ambientales en perspectiva de integralidad, concepto y fundamentación de nuevas demandas y resistencias actuales hacia el "Estado ambiental de derecho". 3 ed. Bogotá. Universidad Nacional de Colombia.

IX. MinAmbiente, (2010). Ministerio de Ambiente, Vivienda y Desarrollo Territorial, Viceministerio de Ambiente, Dirección de Ecosistemas, Grupo de Recurso Hídrico. (2010). Política nacional para la gestión integral del recurso hídrico. Recuperado el 16 de noviembre del 2016 de: https://www.minambiente.gov.co/index.p hp/component/content/article?id=1932:p olitica-nacional-para-la-gestion-integraldel-recurso-hidrico\#documentos-deinter $\% \mathrm{C} 3 \% \mathrm{~A} 9 \mathrm{~s}$

X. MinAmbiente, (2014). Ministerio de Ambiente y Desarrollo Sostenible. Guía técnica para la formulación de los Planes de Ordenación y Manejo de Cuencas Hidrográficas POMCAS. Recuperado el 15 de abril del 2017 de: https://www.minambiente.gov.co/images/ GestionIntegraldelRecursoHidrico/pdf/G u $\%$ C3\%ADa POMCAs $/ 1$. Gu $\%$ C3\%AD a $\mathrm{T} \% \mathrm{C} 3 \% \mathrm{~A} 9 \mathrm{cnica}$ pomcas.pdf
XI. Mondéjar-Pedreño, R. (2015). Los conflictos ambientales y su tratamiento a través de la mediación. Editoral Dykinson.

XII. Naciones Unidas. (2015). Objetivos de desarrollo sostenible. 17 objetivos para transformar nuestro mundo. Recuperado de:

http://www.un.org/sustainabledevelopme $\underline{\text { nt/es/la-agenda-de-desarrollo-sostenible/ }}$

XIII. Rincón-Córdoba, J. (2012). Planes de ordenamiento territorial, propiedad y medio ambiente. Universidad Externado de Colombia. Recuperado de: https://publicaciones.uexternado.edu.co/c atalog/product/view/id/25871/

XIV. Rojas, P. J. (2011). Injusticia hídrica en Colombia: un esbozo. En: Boelens, R., L. Cremers y M. Zwarteveen (2011). Acumulación, conflicto y acción social. Revista Justicia Hídrica. Instituto de Estudios Peruanos y Fondo Editorial Universidad Católica del Perú, Lima. Cap. 16. 279-296. Recuperado el 15 de abril del 2017 de http://justiciahidrica.org/wpcontent/bibtex/pdf/16JH1_Rojas_Cap.16. pdf

XV. Santos-Boaventura, S. (1998). La globalización del derecho: los nuevos caminos y la emancipación. Bogotá. Universidad Nacional de Colombia.

XVI. Valencia-Hernández, J. G. (2007). Estado ambiental, democracia y participación ciudadana en Colombia a partir de la Constitución de 1991. Revista Jurídicas, 
4(2), 172. Recuperado de: http://juridicas.ucaldas.edu.co/downloads /Juridicas4-2_10.pdf

\section{REFERENCIAS JURISPRUDENCIALES}

XVII. CConst, T-411/1992, A. Martínez.

XVIII. CConst, C-058/1994, A. Martínez.

XIX. CConst, T-244/1994, H. Herrera.

XX. CConst, T- 523/1994, A. Martínez.

XXI. CConst, C-671/2001, J. Araújo.

XXII. CConst, C-293/2002, A. Beltrán.

XXIII. CConst, T-410/2003, J. Córdoba.

XXIV. CConst, T-270/2007, J. Araújo.

XXV. CConst, T-418/2010, M. Calle.

XXVI. CConst, C-595/2010, J. Palacios.

XXVII. CConst, C-220/2011, J. Pretelt.

XXVIII. CConst, T-608/2011, J. Henao.

XXIX. CConst, C-094/2015, L. Vargas.

XXX. CConst, T-080/2015, J. Palacio.

XXXI. CConst, C-449/2015, J. Palacio.

XXXII. CConst, T-445/2016, J. Palacio.

XXXIII. CConst, T-622/2016, J. Palacio.

\section{REFERENCIAS NORMATIVAS}

$\begin{aligned} \text { XXXIV. } & \text { D. } 1381 / 1940 . \\ \text { XXXV. } & \text { D. L. } 2811 / 1974 . \\ \text { XXXVI. } & \text { D. } 1449 / 1977 . \\ \text { XXXVII. } & \text { D. } 1541 / 1978 . \\ \text { XXXVIII. } & \text { D. } 2857 / 1981 . \\ \text { XXXIX. } & \text { D. 1594/1984. } \\ \text { XL. } & \text { L. } 79 / 1986 . \\ \text { XLI. } & \text { L. 99/1993, Art. } 111 . \\ \text { XLII. } & \text { L. 1151/2007, Art. } 106 . \\ \text { XLIII. } & \text { L. 1450/2011, Art. } 210 . \\ \text { XLIV. } & \text { D. 953/2013. }\end{aligned}$

XLV. Contraloría General de la República, C. 008/2008.

XLVI. Contraloría General de la República, C. 009/20 
